\title{
UTILIZATION OF RADIATION FROM FISSION PRODUCTS
}

A SYMPOSIUM on the use of fission-product radiation was held by the Chemistry Division at the Atomic Energy Research Establishment, Harwell, during February 23-24. Invited representatives of the chemical and pharmaceutical industries and of those interested in using radiation for food preservation and medical purposes attended the meetings in addition to members of Harwell and of the Radiochemical Centre, Amersham, and the Production Branch of the Directorate of Atomic Energy. The object of the symposium was to decide what steps should be taken now by the Directorate and by potential users if fission-product radiation is to be used fully in the national interest.

In his introduction, Dr. R. Spence (chief chemist at Harwell) said that we should expect by 1970 that the output of fission products could be of the order of one ton per year, representing $2 \times 10^{10} \mathrm{MeV}$.curies (equivalent to $120 \mathrm{MW}$.) from the fissionproduct radiation alone. Even if this energy were used with only 1 per cent efficiency, this represents a considerable power output for such a unique form of energy. Storage of this active material would represent a serious embarrassment to the atomic energy project, and use of the radiation energy from these by-products could reduce the cost of nuclear power.

The first part of the symposium was concerned with the nature of the fission-product sources and with ways of using the radiation energy. In a paper on the use of gamma radiation from reactor fuel rods, Dr. W. Wild and J. Wright (Harwell) discussed ways of storing fuel rods during their 'cooling' period (between irradiation and chemical processing) so that the emitted gamma radiation could be used. Without any interference with present operations, the 70 per cent of the total gamma radiation which is emitted during this period can be used to give dose-rates up to $10^{4} \mathrm{r} . / \mathrm{min}$. A nuclear power station producing $240 \mathrm{MW}$. of electrical power would provide enough fission products to treat 2,000 tons of material per day with a dose of $10^{6} \mathrm{r}$.

A paper by Dr. C. B. Amphlett (Harwell) dealt with the use of the radiation from fission-product wastes and showed that use of the beta energy from the solutions left after chemical processing depends upon fabrication of suitable irradiation vessels with thin portition walls. Calculations of the yield of chemical products obtainable with selected geometrical arrangements show that the most suitable radiation chemical processes for industrial use of fission-product energy would be chain reactions of high yield such as polymerizations, or reactions contributing to the synthesis of some expensive product required only in relatively small quantities. Reactions with yields of less than 10 molecules per $100 \mathrm{eV}$. of energy absorbed are unlikely to compete in output with orthodox chemical industry.

By separating active fission products from inactive material very high specific activity aan be obtained so that self-absorption in the source is reduced to a minimum. The total production of many of the longerlived fission products can be utilized efficiently throughout much of their life, leaving relatively inactive end-products. This was discussed by G. N. Walton (Harwell) in a paper on the specific activity of separated fission products from reactor fuels. Following the principle that the shorter the life of the fission product concerned, the less is the mass of material involved in the transfer of power, calculations were made of the power which would be carried by short-lived rare-gas fission products which might be removed direct from the reactor core and piped past the target material.

The separation of long-lived fission products was discussed by P. E. Carter (Amersham) by reference to the chemical processes and plant used for separation of several curies per year of strontium-90 and cæsium-137. 'The description of this plant, which may serve as a prototype for large-scale separation of these fission products, illustrated some of the problems which will be met in preparing large sources of high specific activity.

In discussing the value of these different types of fission-product source, it was emphasized that efficient utilization of the radiation requires these materials to be used continuously as they are produced and at all stages of their decay. The removal of short-lived fission products during operation of the reactor would involve modifications to the design of the latter but might lead to improved performance, since some of the fission products are nuclear 'poisons'. The time during which fuel rods could be used as gamma sources might be reduced in future irradiation and 'cooling' schedules; but the use of fuel enriched in the fissile component would lead to higher specific activities after irradiation and would reduce self-absorption of radiation in the source. Use of the fuel rods or of the waste solutions at the concentration at which they would normally be stored would involve only the construction of suitable irradiation vessels.

There seemed no doubt of the technical feasibility of producing sources of megacurie activity which would be required for most large-scale uses of fissionproduct radiation; but it was emphasized that the initial capital cost would be very great. The present chemical-separation plant is designed to treat fission products as an objectionable by-product; modifications to enable their radiation energy to be used would be more costly than incorporation of these requirements in new plant. The cost of plant for handling aative materials is, in any event, greater than that of ordinary chemical plant, not only because of the protection problems involved but also because of the difficulty of maintenance. This imposes severe restrictions on the methods and materials used for what are normally quite simple operations. The cost of concentrating waste solutions beyond the level at which they would normally be stored and the cost of separating individual fission products will be considerable and must be shared between the atomic energy project and the user of the source in accordance with the advantages derived by each.

The second session of the symposium, with Dr. W. Wild (Harwell) as chairman, was devoted to consideration of the uses of fission-product radiation in the chemical, pharmaceutical and food industries. M. W. Perrin (Wellcome Foundation, Ltd.), in a paper on the technical feasibility of the use of fission products, said that many of the radiation sources will be available only at the reactor sites or at the site of the chemical separation plant. This may 
contribute to the general re-location of industry both within Great Britain and between countries, this being, in any event, a likely consequence of the development of nuclear power. It is not yet known what radiation chemical reactions are likely to be of value in the industrial field, and the main need at present is for an extended survey of the chemical effects of radiation. It would greatly assist industrial research laboratories in studying systems of special commercial interest to them if they could draw upon men who had been taught the basic facts of radiation chemistry in the course of their university career. As an example of work of special commercial interest, L. Seed (Alkali Division, Imperial Chemical Industries, Ltd.) described some experiments in which an increase in rate of polymerization of ethylene was observed in the presence of gamma radiation from cobalt. Even with a source of only $\frac{1}{2}$ curie, the presence of a gamma-induced reaction could be detected by subtracting the value for the 'thermal' reaction.

Dr. J. W. Barrett, B. L. Budd, Dr. R. Roberts and Dr. D. S. P. Roebuck (Monsanto Chemicals, Ltd.) presented a paper on the economic feasibility of the use of fission products, which showed how the economics of a medium-sized ehemical plant are worked out and the influence upon these figures of the cost of radiation sources. Until more technical data are available on radiation chemical reactions, yields and rates, it will not be possible to assess the economic advantages of using radiation. A profitable radiation-induced reaction should be sought among those processes for which capital expenditure and process costs are more important than the cost of raw materials.

In a paper on the preservation of food, Dr. R. S. Hannan (Low Temperature Researoh Station, Cambridge) summarized the present position of research into the use of ionizing radiations for sterilizing food. It has been established that doses of the order of $2 \times 10^{6} \mathrm{r}$. are necessary, and efforts are now being directed to eliminate the deleterious taste and odour which often result from this method of sterilization. The full techniques finally developed may prove too complex for economic application, except for very special products ; but if the process does prove practicable on a wider rangu of eommon foodstuffs, many megacurie sources will eventually be required.

W. Jones (Imperial Chemical (Pharmaceuticals), Ltd.) read a paper on the sterilization of pharmaceutical products, which compared present methods of attaining sterility with what is known about the use of radiation for this purpose. While there is a place in the industry for an improved sterilization process, most large manufacturers are already equipped to operate older methods, and a suitable process for small manufacturers must be of low initial cost and economic in use. The advantages of using fission-product radiation-low maintenance cost and ability to sterilize the product in its final container-may ultimately prevail, but much more work is still required.

The last two papers in this session dealt with the effect of ionizing radiation on the physical properties and molecular structure of pre-formed plastics and of synthetic and natural high polymers. Speaking on high-energy radiation and long-chain polymers, Dr. A. Charlesby (Harwell) dealt with the physical changes in such substances as polythene, rubber, polystyrene and 'Perspex' subjected to pile radiation.
The observed effects were interpreted in terms of eross-linking between polymer chains and other structural changes. Dr. K. Little (Harwell), in a paper on the effects of ionizing radiation on organic high polymers, attributed the observed changes to many chemical effects, of which cross-linking is only one. Experimental evidence for these conclusions was derived from examination of many fibres ('Orlon', nylon, silk, viscose, e $e^{\dagger} c$.) which had been irradiated in the pile.

In the course of the discussion it became clear that there is not sufficient information in either the technical or economic sphere to assess the potentialities of using fission-product radiation in the chemical industry. University research departments could help a great deal by building up a systematic chemistry of radiation effects. The economic assessment awaits more realistic estimates of the cost of producing sources of high specific activity. The type of source required, the site at which it is to be used, the design of irradiation vessel and many other factors are all dependent on the processes to be worked. Guidance on these points is needed at an early stage if full advantage is to be taken of the radiation energy as soon as it becomes available.

Technical feasibility in the preservation of food and sterilization of pharmaceutical products is less in doubt, and some idea of the required doses is already available. With materials for human consumption, however, many very important safety aspects arise. Most of the gamma-rays from fission products are of too low an energy to give appreciable activity through the neutrons produced by $(\gamma, n)$ processes ; but this aspect must be checked, especially for the short-lived fission products. It must also be established beyond reasonable doubt that toxic compounds, including carcinogens, are not produced. in irradiated material and that consumption of that material on a large scale and over long periods will have no harmful effects. These are formidable obstacles; but the potential value of the method is great.

In regard to the medical aspects of the subject, it was emphasized that the handling and utilization of megacurie sources would be intrinsically very dangerous, and an important part of the energy and cost of development of the new methods must be applied to these protection problems.

The third session dealt with separated fission products, for many of which important uses have already been found, and this session was therefore less speculative in nature than the earlier ones. Prof. W. V. Mayneord (Royal Cancer Hospital, London), who presided at this session, outlined some of the medical uses of radiation, pointing out that the overall amounts of material required for these purposes are likely to be very much less than the total production; kilocuries of some isotopes, such as cæsium-137, would, however, be required.

Dr. W. P. Grove (Amersham) described methods of mounting separated fission products safely for industrial and medical use. By forging active oxides or salts into silver or other metals, thin foils or plaques can be obtained in which the beta activity suffers little self-absorption and from which no active contamination is removed by rubbing, boiling in water, or similar treatment.

In a paper on cæsium-137 and its use, W. S. Eastwood (Harwell) pointed out that this isotope has a very long-lived beta-gamma emission which is likely to be valuable in medicine for radiotherapy. 
Sources of about 5,000 curies mounted in a $5-\mathrm{cm}$. cube could be used in place of an X-ray teletherapy unit and, unlike the latter, could not fail at a critical moment. Such cæsium-137 sources would also be ideal for use by industry in research and development on radiation chemistry. Dr. J. W. Arrol (Harwell) described the handling and uses of some other fission products. Iodine-131 is used extensively in medicine, and the plant for its large-scale production from fission products was described. The rare gas, krypton-85, is particularly valuable because of its chemical inertness and its radioactive long life. The fact that it is almost a pure beta-emitter makes it possible to handle very high activity sources with little shielding. Its use as a static eliminator, in ventilation control, and for sterilization of blood plasma was suggested.

As a result of this symposium it became clear that the following steps should be taken if the full and efficient use of the radiation from fission products is to be ensured in Great Britain. The assistance of university research departments should be enlisted in an effort to build up gradually a systematic chemistry of radiation effects, particularly in mixtures of organic substances. Industrial research laboratories should be encouraged to use the sources now becoming available to carry out short-term studies of radiation effeats which may be of special interest to them. The technical problems of preventing unpleasant taste and odour and of ensuring safety of the product clearly require further attention in the field of food preservation and pharmaceutical sterilization. Realistic estimates of the cost of making available large fission-product sources from existing and from future plant should be prepared. Plans already made for the production of sources of high specific activity from fission-product wastes should be implemented, since this will not only provide sources for medical and industrial use but will also furnish the basic information needed for technical and economic estimates of future large-scale production of sources.

As information becomes available from this work, the overall advantages of using fission-product radiation must be assessed on a national basis and, by close collaboration between the atomic energy project and potential users, a scheme should be worked out for apportioning the additional cost of providing the facilities.

The papers presented at this symposium, together with a full account of the discussion, are being prepared as a Harwell report, and will be on sale at Her Majesty's Stationery Office. The present account is published by permission of the Director of the Atomic Energy Research Establishment.

$$
\text { G. N. WALTON }
$$

J. WRIGHT

\section{SOLUTIONS OF ELECTROLYTES IN ORGANIC SOLVENTS}

A SYMPOSIUM on "Solutions of Electrolytes in Organic Solvents" was held at Buckland House, Buckland, Berks, on April 15 by invitation of the Physical Chemistry Group of the Atomic Energy Research Establishment, Harwell. About fifty people attended, including visitors from various universities and institutions in the United Kingdom and overseas. The meeting was under the chairmanship of Dr. E. Glueckauf (Harwell), who, in his opening remarks, said that the nine papers to be discussed were grouped into three sections : solvent extraction and the nature of addition complexes; acid-base phenomena in nonaqueous solutions; and the constitution of solutions contrining iodine.

The first paper, by T. V. Healy and Dr. G. M. Waind (Harwell), was on "The Extraction of Metal Nitrates into Phosphate Esters". Mr. Healy discussed the differences in the extraction of cobalt, sodium, and uranyl nitrates from aqueous solutions by tributyl phosphate, and also partition data for uranyl nitrate between water and the solvents dibutylphenyl phosphate, diphenylbutyl phosphate and triphenyl phosphate. He showed that the thermodynamic equilibrium constants and free energies of transfer of uranyl nitrate between the various solvents are in the order expected from the electron-donor properties of the solvents. Deviations from ideality above $0 \cdot 1 M$ were used for estimating approximate solvation numbers for the complexes (for example, $n=2$ for $\left.\mathrm{UO}_{2}\left(\mathrm{NO}_{3}\right)_{2} \cdot n(\mathrm{BuO})_{3} \mathrm{PO}\right)$. More accurate values were obtained from partition data (with organic concentrations $<0.1 M$ ) in the presence of inert diluents, in conjunction with solvent activities obtained from vapour-pressure measurements.

Dr. H. M. Feder (Argonne National Laboratory, Chicago), in a paper entitled "The Stability of Molecular Addition Compounds : a Solubility Technique", dealt with the formation of compounds between mercuric chloride and various alcohols and carbonyl compounds in carbon tetrachloride. Although equilibrium was reached more slowly in organic media than in aqueous solutions, the results were reproducible, and enthalpy, free energy and entropy changes for the reactions were evaluated with good precision. After discussing the applicability and limitations of the solubility technique, Dr. Feder presented results on uranyl nitrate dihydrate with a wide variety of organic bases (donors). Formation constants thus obtained were compared in terms of the general Lewis acid - base theory, as modified by steric requirements.

The discussion on these two papers was opened by Prof. W. F. K. Wynne-Jones (Newcastle upon Tyne), who criticized the use of the term 'base strength' when applied to Lewis donor species. He pointed out that the term can be precisely and usefully defined in the conventional way in aqueous systems, and showed that an attempt to generalize this to obtain a sequence of base strengths valid for all systems merely results in a confused state where a unique order is not even defined within the one solvent. This was supported by Prof. J. A. A. Ketelaar (Amsterdam). In answer to R. P. Bell (Oxford), Mr. Healy said that the water content and electrical conductivity of sodium nitrate solutions in phosphate esters have not
yet been determined.

In the session before luncheon, two papers were read from the Atomic Energy Research Establishment, Harwell. H. A. C. McKay, who spoke on "The Partition of Nitric Acid between Water and Ethers", considered first the binary water - ether systems. The differential heats of mixing indicate compound formation, and the water-vapour pressure curve in the water - pentaether system indicates interaction between the dissolved water molecules in the pentaether. In polyethers, the oxygen atoms appear to act independently of each other when forming complexes with water or uranyl nitrate. Mr. McKay said that conductivity and viscosity measurements show that, in most cases, the nitric acid may be considered as 